\title{
UJI KOMPERASI SEKAM PADI SEBAGAI BAHAN BAKAR PADA ALAT BOILER PENGHANGAT TERNAK AYAM
}

\author{
Jusman Rauf $^{1)}$, Burhan liputo ${ }^{2)}$, Iqrima Staddal ${ }^{3)}$ \\ ${ }^{1)}$ Mahasiswa Program Studi Mesin dan Peralatan Pertanian, Politeknik Gorontalo \\ ${ }^{2,3)}$ Dosen Program Studi Mesin dan Peralatan Pertanian, Politeknik Gorontalo
}

\begin{abstract}
ABSTRAK
Pengusaha atau wirausahawan ternak ayam pedaging di Gorontalo, memiliki kendala dalam budidaya ayam pedeging. Dalam mewujudkan peningkatan produksi peternakan di Gorontalo, masyarakat Gorontalo bertujuan mengembangkan kualitas ternak, khususnya ternak ayam pedaging. Kandang ternak yang ada di Gorontalo sudah menggunakan beberapa metode pengembangan untuk pemanas kandang ternak, agar kualitas ternak ayam yang lebih unggul. Pemanas kandang ternak yang ada di Gorontalo seperti Gas Brooder yang menggunakan bahan bakar gas LPG, tetapi dilihat pada kalangan ekonomi lemah metode tersebut sangat tidak ekonomis. peneltian ini bertujuan untuk,Mengetahui berapa besar suhu yang terjadi pada saat pembakaran sekam padi didalam boiler, mengetahui berapa lama ukuran temperatur suhu pada saat pembakaran sekam padi didalam boiler. Sekam ini memiliki kerapatan jenis (bulk densil) $1125 \mathrm{~kg} / \mathrm{m} 3$, dengan nilai kalori $1 \mathrm{~kg}$ sekam sebesar $3300 \mathrm{k}$. kalori, serta memiliki bulk density $0,100 \mathrm{~g} / \mathrm{ml}$, nilai kalori antara $3300-3600$ kkalori/kg sekam dengan konduktivitas panas 0,271 BTU (Houston, 1972). Boiler adalah bejana tertutup dimana panas pembakaran dialirkan ke air sampai terbentuk air panas atau steam. Kegiatan penelitian ini mulai dilaksanakan pada Oktober 2018 sampai dengan Juli 2019 di Laboratorium Mesin Umum dan Welding Program Studi Mesin dan Peralatan Pertanian Politeknik Gorontalo. Proses pengujian alat, berguna untuk mengetahui cara kerja alat dan efesiensi alat penghangat ternak ayam. Pada saat pengujian alat simulator boiler berbahan bakar sekam padi pada ternak ayam dilakukan percobaan sebanyak tiga kali dengan berat sekam $1 \mathrm{~kg}, 2 \mathrm{~kg}$ dan $3 \mathrm{~kg}$ yang masing-masing dilakukan selama satu jam. hasil percobaan pada Gas Brooder menghabiskan bahan bakar berupa gas sebanyak $3 \mathrm{~kg}$ dalam waktu 19:00 - 06:00. Untuk simulator boiler berbahan bakar sekam menghabiskan sekam padi 6kg, namun keunggulan dari alat simulator boiler ini mudah untuk mendapatkan bahan bakarnya. Sekam mudah ditemukan didekat penggilingan padi, adapun dijual harganya tak semahal harga gas. Sedangkan untuk pemanas gas brooder ini, sulit untuk mendapatkan bahan bakarnya. Dilihat dari kondisi gas yang disediakan oleh pemerintah Gorontalo sangatlah minim untuk kebutuhan masyrakat Gorontalo
\end{abstract}

Keyword : Simulator, Boiler, Sekam Padi, Ternak ayam

\section{ABSTRACT}

\section{CHICKEN HOUSING COMPERATION TEST AS A FUEL ON CHICKEN BOILER WARMING TOOLS)}

The businessman and entrepreneur of broiler cattle in Gorontalo has an obstacle in the cultivation of pedeging chicken. In realizing the increase of livestock production in Gorontalo, Gorontalo community aims to develop the quality of livestock, especially cattle broiler. Livestock cage in Gorontalo has used several methods of development for the heating of livestock cage, so that the quality of chicken cattle is superior. Cage heater that exists in Gorontalo such as Gas Brooder that uses LPG gas, but seen in the weak economy of the method is very uneconomical. This research aims to, know how much temperature that occurs at the time of combustion of rice husk in the boiler, knowing how long the temperature of the temperatures at the time of combustion rice husk in the boiler. This husk has density (bulk densil) $1125 \mathrm{~kg} / \mathrm{m} 3$, with a calorie value of $1 \mathrm{~kg}$ husk at $3300 \mathrm{~g}$. 
Calories, and has a bulk density of $0.100 \mathrm{gr} / \mathrm{ml}$, calorie value between 3300-3600 kcalorie/kg husk with heat conductivity 0.271 BTU (Houston, 1972). Boiler is a sealed vessel where heat combustion is flowing into the water until the form of hot water or steam. This research activity began to be held in October 2018 until July 2019 in general Machine Laboratory and Welding Program of machinery studies and agricultural equipment of Gorontalo Polytechnic. Tool testing process, useful to know how to work tools and efficiency of poultry heating equipment. At the time of testing of the simulator tool boiler-fueled rice husk on the chicken cattle Experiment three times with the weight of $1 \mathrm{~kg}, 2 \mathrm{~kg}$ and $3 \mathrm{~kg}$ that each was done for an hour. The results of the experiment on Gas Brooder spent gas fuel as much as 3kg within 19:00 - 06:00. For the simulator of boiler fueled husk spends 6kg rice husk, but the advantages of this boiler simulator tool is easy to get the fuel. Husk is easily found near rice milling, as for sale The price is not as expensive as gas prices. As for this brooder gas heater, it is difficult to get fuel. Judging from the gas condition provided by the Government of Gorontalo is very minimal for the needs of Gorontalo

\section{Keyword: Simulator, Boiler, Rice Husk, Chicken Husbandry}

\section{PENDAHULUAN}

Propinsi Gorontalo memiliki komoditas pertanian yang cukup banyak, dimana sebagian besar penduduknya bekerja dibidang pertanian. Salah satu produk pertanian di Gorontalo adalah padi. Kepala bidang pusat statistik Propinsi Gorontalo Eko Marsoron, mengatakan luas panen dan produk padi di Propinsi Gorontalo 2018, 51.765 hektar, 241.948 ton gabah kering giling, 134.399 ton beras dan jumlah limbah padi berupa sekam dari hasil pengolahan padi sebanyak 107.549 ton (BPS, 2018). Pemanfaatan sekam padi didaerah ini secara umum masih belum optimal. Selama ini di Gorontalo sekam padi hanya dimanfaatkan untuk pakan ternak, media bercocok tanam, bahan bakar pada pembakaran batu merah, campuran pembuatan batu bata atau tidak dimanfaatkan. Pemanfaatan sekam padi dikalangan pengusaha ayam ternak berupa pembakaran yang dilakukan dibawah kandang ayam, tujuanya untuk menghangatkan ayam yang di dalam kandang. Namun usaha tersebut jauh dari kata efisien, karena sumber penghangat ayam ternak belum dapat dikontrol atau dikendalikan dengan baik, karena masih mengunakan cara konvensional.

Pengusaha atau wirausahawan ternak ayam pedaging di Gorontalo, memiliki kendala dalam budidaya ayam pedeging. Dalam mewujudkan peningkatan produksi peternakan di Gorontalo, masyarakat Gorontalo bertujuan mengembangkan kualitas ternak, khususnya ternak ayam pedaging. Kandang ternak yang ada di Gorontalo sudah menggunakan beberapa metode pengembangan untuk pemanas kandang ternak, agar kualitas ternak ayam yang lebih unggul. Pemanas kandang ternak yang ada di Gorontalo seperti Gas Brooder yang menggunakan bahan bakar gas LPG, tetapi dilihat pada kalangan ekonomi lemah metode tersebut sangat tidak ekonomis

\section{TINJAUAN PUSTAKA}

\section{Karakteristik Fisik Sekam}

Sekam padi merupakan lapisan keras yang meliputi kariopsis yang terdiri dari dua belahan yang disebut lemma dan palea yang saling bertautan. Pada proses penggilingan beras sekam akan terpisah dari butir beras dan menjadi bahan sisa atau limbah penggilingan. Sekam dikategorikan sebagai biomassa yang dapat digunakan untuk berbagai kebutuhan seperti bahan baku industri, pakan ternak dan energi atau bahan bakar.

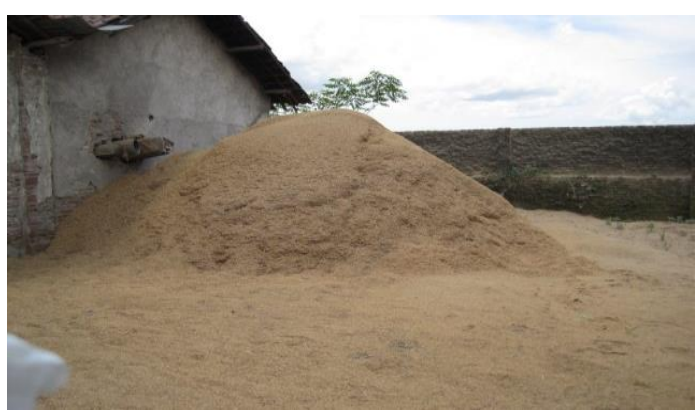

Gambar 2.1. Sekam Padi

\section{Komposisi sekam padi dan abu sekam padi}


Sekam memiliki kerapatan jenis (bulk densil) $1125 \mathrm{~kg} / \mathrm{m} 3$, dengan nilai kalori $1 \mathrm{~kg}$ sekam sebesar $3300 \mathrm{k}$. kalori, serta memiliki bulk density $0,100 \mathrm{~g} / \mathrm{ml}$, nilai kalori antara $3300 \quad-3600$ kkalori/kg sekam dengan konduktivitas panas 0,271 BTU (Houston, 1972). Sekam dikategorikan sebagai biomassa yang dapat digunakan untuk berbagai kebutuhan seperti bahan baku industri, pakan ternak dan energi atau bahan bakar ataupun sebagai adsorpsi pada logam-logam berat. Sekam tersusun dari jaringan serat-serat selulosa yang mengandung banyak silika dalam bentuk serabutserabut yang sangat keras. Pada keadaan normal, sekam berperan penting melindungi biji beras dari kerusakan yang disebabkan oleh serangan jamur, dapat mencegah reaksi ketengikan karena dapat melindungi lapisan tipis yang kaya minyak terhadap kerusakan mekanis selama pemanenan, penggilingan dan pengangkutan (Houston, 1972).

\section{Pemanfaatan sekam padi di bidang industri}

Sumber silika sekitar $20 \%$ silika dalam sekam padi merupakan suatu sumber silika yang cukup tinggi, silika dari sekam merupakan saingan dari sumber silika lain seperti pasir, bentonit dan tanah diatomae tetapi biasanya silika dari sekam padi mempunyai keuntungan karena jumlah elemen lain (pengotor) yang tidak diinginkan adalah sangat sedikit dibandingkan jumlah silikanya. Silika diperoleh dari pembakaran sekam untuk menghasilkan abu atau secara ekstraksi sebagai natrium - silikat dengan larutan alkali (Houston, 1972).

$>$ Pemurnian air pemanfaatan sekam antara lain sebagai sumber energi, abu gosok yaitu untuk keperluan rumah tangga, bahan pencampur untuk pembuatan semen portland dalam bidang industri, selain itu untuk menjernihkan air. Pemanfaatan sekam padi untuk menjernihkan air yaitu melalui proses filtrasi/penyaringan partikel, koagulasi dan adsorpsi. Akan tetapi karbon yang terkandung didalam sekam padi berfungsi sebagai koagulan pembantu dengan menyerap atau menurunkan logam - logam pada air yang tercemar (Houston, 1972).

> Bahan bakar pembakaran merupakan satu metode yang umum dan sering digunakan dalam proses akhir pengolahan sekam padi. Sekam padi yang dibakar secara langsung untuk meneruskan aliran uapnya atau digunakan di dalam generator untuk menghasilkan tenaga penguat dengan minyak yang memiliki nilai bahan bakar (Houston, 1972).

> Bahan bangunan manfaat sekam padi adalah sebagai bahan bangunan yang berhubungan dengan pengerasan balok, batu bata, ubin, batu tulis dan sifat lunak. Yang dapat dimanfaatkan sesuai dengan fungsinya (Houston, 1972).

\section{Simulator Boiler}

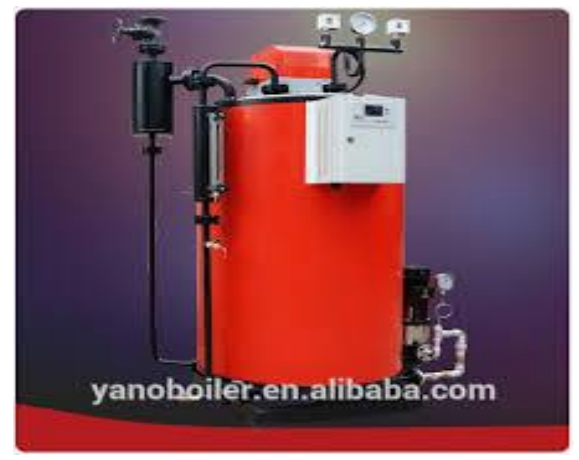

Gambar 2.2 Simulator boiler

Boiler adalah bejana tertutup dimana panas pembakaran dialirkan ke air sampai terbentuk air panas atau steam. Air panas atau steam pada tekanan tertentu kemudian digunakan untuk mengalirkan panas ke suatu proses. Air adalah media yang berguna dan murah untuk mengalirkan panas ke suatu proses. Jika air dididihkan sampai menjadi steam, volumnya akan meningkat sekitar 1.600 kali, menghasilkan tenaga yang menyerupai bubuk mesiu yang mudah meledak, sehingga boiler merupakan peralatan yang harus dikelola dan dijaga dengan sangat baik (Termis, 2008).

\section{$\checkmark$ Jenis - jenis boiler}

Bagian ini menerangkan tentang berbagi jenis boiler: Fire tube boiler, Water tube boiler, Paket boiler, Fluidized bed combustion boiler, Atmospheric fluidized bed combustion boiler, Pressurized fluidized bed combustion boiler, Circulating fluidized bed combustion boiler, Stoker fired boiler, Pulverized fuel boiler, Boiler pemanas limbah (Waste heat boiler) dan Pemanas fluida termis (Termis, 2008).

\section{$>$ Fire tube boiler}

Pada fire tube boiler, gas panas melewati pipa-pipa dan air umpan boiler ada didalam shell untuk dirubah menjadi steam. Fire tube boilers 
biasanya digunakan untuk kapasitas steam yang relative kecil dengan tekanan steam rendah sampai sedang. Sebagai pedoman, fire tube boilers kompetitif untuk kecepatan steam sampai 12.000 $\mathrm{kg} / \mathrm{jam}$ dengan tekanan sampai $18 \mathrm{~kg} / \mathrm{cm} 2$. Fire tube boilers dapat menggunakan bahan bakar minyak, gas atau bahan bakar padat dalam operasinya. Untuk alasan ekonomis, sebagian besar fire tube boilers dikonstruksi sebagai " paket" boiler (dirakit oleh pabrik) untuk semua bahan bakar (Termis, 2008).

\section{$>$ Water tube boiler}

Pada water tube boiler, air umpan boiler mengalir melalui pipa-pipa masuk kedalam drum. Air yang tersirkulasi dipanaskan oleh gas pembakaran membentuk steam pada daerah uap dalam drum. Boiler ini dipilih jika kebutuhan steam dan tekanan steam sangat tinggi seperti pada kasus boiler untuk pembangkit tenaga. Water tube boiler yang sangat moderen dirancang dengan kapasitas steam antara $4.500-12.000 \mathrm{~kg} / \mathrm{jam}$, dengan tekanan sangat tinggi. Banyak water tube boilers yang dikonstruksi secara paket jika digunakan bahan bakar minyak bakar dan gas. Untuk water tube yang menggunakan bahan bakar padat, tidak umum dirancang secara paket. Karakteristik water tube boiler sebagai berikut: Forced, induced dan balanced draft membantu untuk meningkatkan efisiensi pembakaran Kurang toleran terhadap kualitas air yang dihasilkan dari plant pengolahan air. Memungkinkan untuk tingkat efisiensi panas yang lebih tinggi (Termis, 2008).

\section{$>$ Paket boiler}

Disebut boiler paket sebab sudah tersedia sebagai paket yang lengkap. Pada saat dikirim ke pabrik, hanya memerlukan pipa steam, pipa air, suplai bahan bakar dan sambungan listrik untuk dapat beroperasi. Paket boiler biasanya merupakan tipe shelland tube dengan rancangan fire tube dengan transfer panas baik radiasi maupun konveksi yang tinggi. Ciri-ciri dari packaged boilers adalah: Kecilnya ruang pembakaran dan tingginya panas yang dilepas menghasilkan penguapan yang lebih cepat. Banyaknya jumlah pipa yang berdiameter kecil membuatnya memiliki perpindahan panas konvektif yang baik (Termis, 2008).

\section{Panas Thermal Sekam Padi}

Nilai konduktivitas thermal terbaik diperoleh pada papan partikel sekam padi dengan kepadatan 3-1 diperoleh angka konduktivitas termal $0,133 \mathrm{~W} / \mathrm{m}^{\circ} \mathrm{C}$ dengan sumber kalor 70 watt dan $0,103 \mathrm{~W} / \mathrm{m}^{\circ} \mathrm{C}$ dengan sumber kalor 80 watt. Angka konduktivitas termal pada kepadatan 6-1 dengan angka konduktivitas termal sebesar $0,096 \mathrm{~W} / \mathrm{m}^{\circ} \mathrm{C}$ pada sumber kalor 70 watt dan $0,082 \mathrm{~W} / \mathrm{m}^{\circ} \mathrm{C}$ pada sumber kalor 80 watt. Adapun angka konduktivitas perpindahan kalor papan gabus (Styrofoam) ratarata diperoleh sebesar $0,095 \mathrm{~W} / \mathrm{m}^{\circ} \mathrm{C}$ (Wibowo, 2008).

\section{Jenis - Jenis Alat Penghangat Ternak Ayam \\ $\checkmark$ Pemanas Gasolec}

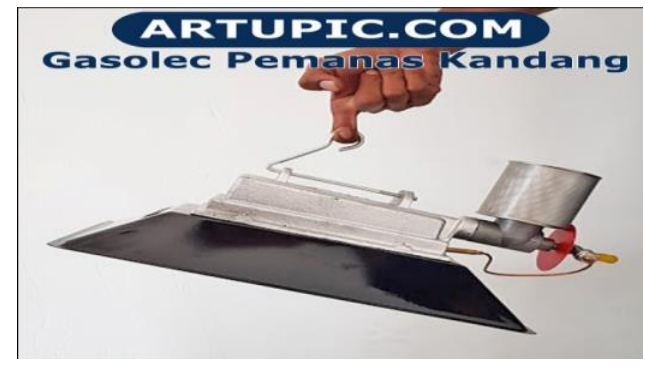

Gambar 2.3. Pemanas Gasolec

Pemanas kandang ayam gasolec mampu menjaga stabilitas suhu dalam kandang dengan jenis bahan bakar elpiji yang mudah didapatkan.

Keterangan:

1) Bahan bakar : Elpiji

2) Kapasitas : 1 pemanas untuk $500-1000$ ekor ayam

3) Dimensi : P $45 \mathrm{~cm} \times \mathrm{L} 31 \mathrm{~cm} \times \mathrm{T} 21.5 \mathrm{~cm}$

4) Kelengkapan : Filter

5) Konsumsi bahan bakar : 250 gr / jam Regulator max.

\section{Pemanas IGM}

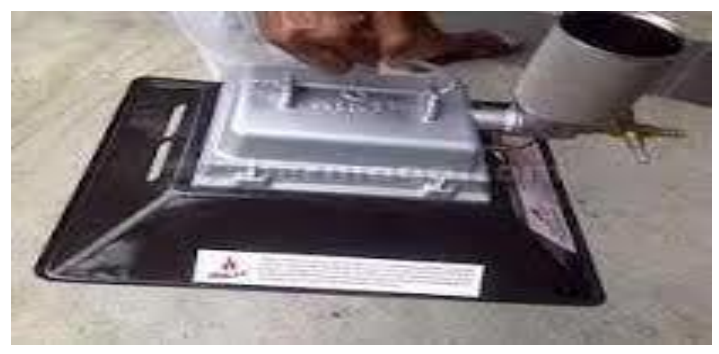

Gambar 2.4. Pemanas IGM 
Pemanas kandang ayam buatan dari Medion ini dapat menghemat bahan bakar serta mudah dalam penggunaan. Termasuk juga suhu yang bisa diatur agar stabil dan menyesuaikan kondisi kelembaban kandang ayam.

Keterangan:

1) Bahan bakar : Elpiji

2) Kapasitas : 1 pemanas untuk $700-1000$ ekor ayam.

3) Dimensi : $46.5 \mathrm{~cm} \times 34 \mathrm{~cm} \times 23.5 \mathrm{~cm}$

4) Kelengkapan : Filter

5) Konsumsi bahan bakar : 128 - 225 gram gas LPG/jam.

\section{METODE PENELITIAN}

\section{Diagram Alir}

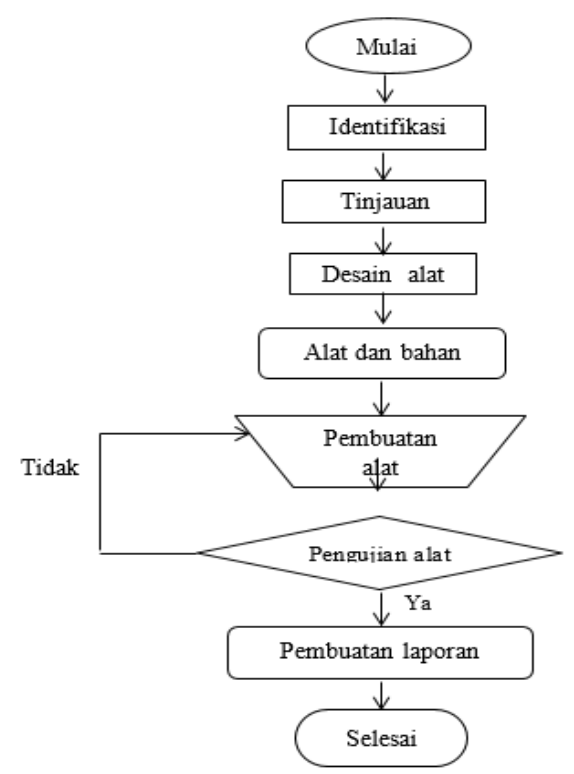

Gambar 3.1. Diagram Alir.

\section{Indentifikasi Masalah}

Pegusaha atau wirausahawan ternak ayam pedaging di Gorontalo memiliki kendala dalam budidaya ayam pedaging. Masalah yang dihadapi para peternak ayam, salasatunya dalam pemberian panas. Ada dua, metode yang digunakan pada pemberian panas untuk ayam diantaranya.

\section{Cara tradisional}

Memanfaatkan limbah dari hasil pertanian untuk dijadikan bahan bakar, dengan cara membakar limbah pertanian dibawah kandang ayam dan sumber panas belum dapat dikontrol.

\section{Pemanas Gas Brooder}

Dilihat pada kalangan ekonomi rendah alat ini belum bisa menjadi solusi, karena bahan bakar yang digunakan berupa gas. Keungulan alat ini dapat mengontrol panas yang dibutuhkan ayam.

\section{Desain Alat}

Desain alat yaitu mendesain konsep alat yang akan dibuat dengan mengetahui kelebihan dan kekurangan dari alat sebelumnya, setelah mengetahui semua kelemahan dan kekurangan maka penulis mendesain. Alat penghangat ternak ayam jenis pedaging dengan sistem simulator boiler mengunakan bahan bakar sekam padi.

\section{Desain alat}

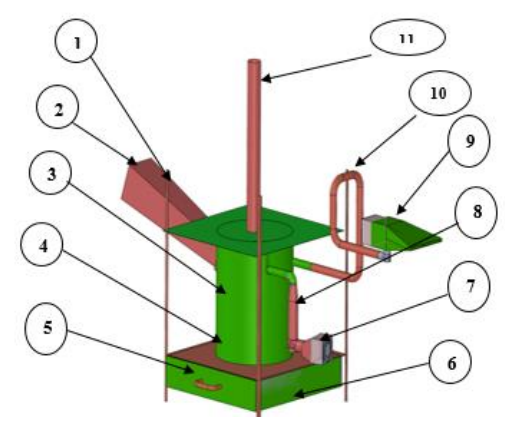

Gambar 3.2. Desain Alat Penghangat Ternak Ayam

Keterangan

\section{Rangka Alat}

2. Hopper Bahan bakar

3. Boiler

4. Plat Saringan

5. Laci Penampung

6. Kipas

7. Input (Udara masuk)

8. Output (udara keluar)

9. Selang Penghantar Aliran Uap (keluar)

10. Plat Penutup Atas

11. Corong Penguapan

\section{Perancangan fungsional}

Perancangan fungsional merupakan fungsi dari setiap komponen alat yang akan di rancang dan dibuat. Komponen-komponen alat penghangat 
ternak ayam jenis pedaging, antara lain terdapat pada table 3.1.

Tabel 3.1.Fungsi setiap komponen pada alat penghangat ternak ayam.

\begin{tabular}{|c|c|c|}
\hline No & Komponen & Fungsi Utama \\
\hline 1. & Rangka Alat & $\begin{array}{l}\text { landasan atau penopang untuk } \\
\text { semua komponen - komponen } \\
\text { alat. }\end{array}$ \\
\hline 2. & $\begin{array}{l}\text { Hoper Bahan } \\
\text { Bakar }\end{array}$ & $\begin{array}{l}\text { Tempat masuknya bahan bakar } \\
\text { berupa sekam padi pada proses } \\
\text { pembakaran di dalam boiler. }\end{array}$ \\
\hline 3. & Boiler & $\begin{array}{l}\text { Sumber panas untuk proses } \\
\text { penguapan yang akan } \\
\text { dimanfaatkan uapnya utuk } \\
\text { memanaskan ternak ayam. }\end{array}$ \\
\hline 4. & Plat Saringan & $\begin{array}{l}\text { tempat keluar bahan bakar } \\
\text { yang sudah terbakar berupa } \\
\text { debu. }\end{array}$ \\
\hline 5. & $\begin{array}{l}\text { Laci } \\
\text { Penampung }\end{array}$ & $\begin{array}{l}\text { untuk menampung hasil dari } \\
\text { sisah pembakaran yang sudah } \\
\text { tersaring agar tempat } \\
\text { pembakaran mudah untuk } \\
\text { dibersikan. }\end{array}$ \\
\hline 6. & Kipas & $\begin{array}{l}\text { Sumber udara/oksigen untuk } \\
\text { proses pembakaran pada boiler } \\
\text { dan pengatur laju, lambat } \\
\text { aliran udara. }\end{array}$ \\
\hline 7. & $\begin{array}{l}\text { Imput } \\
\text { masuk }\end{array}$ & $\begin{array}{l}\text { Menerima udara dari kipas } \\
\text { agar udara tersebut dapat } \\
\text { bersirkulasi ke tempat } \\
\text { pembakaran/boiler. }\end{array}$ \\
\hline 8. & $\begin{array}{l}\text { Output uap } \\
\text { keluar }\end{array}$ & $\begin{array}{l}\text { Tempat keluar udara yang } \\
\text { sudah bersirkulasi dari hasil } \\
\text { pembakar }\end{array}$ \\
\hline 9. & $\begin{array}{l}\text { Selang } \\
\text { penghantar } \\
\text { udara }\end{array}$ & $\begin{array}{l}\text { Tempat udara/oksigen } \\
\text { bersikulasi ke output }\end{array}$ \\
\hline
\end{tabular}

\begin{tabular}{|l|l|l|}
\hline 10. & $\begin{array}{l}\text { Plat Penutup } \\
\text { Atas }\end{array}$ & $\begin{array}{l}\text { menutup tempata } \\
\text { pembakaran agar udara/asap } \\
\text { keluar pada tempatmya }\end{array}$ \\
\hline 11. & $\begin{array}{l}\text { Corong } \\
\text { Penguapan }\end{array}$ & $\begin{array}{l}\text { Tempat keluarnya uap bakar } \\
\text { yang terjadi pada proses } \\
\text { pembakaran }\end{array}$ \\
\hline 12. & $\begin{array}{l}\text { Tengontrol suhu/uap yang } \\
\text { Thermocouple } \\
\text { dihasilkan dari alat dan } \\
\text { mengatur suhu sesuai yang } \\
\text { dibutuhkan ternak ayam. }\end{array}$ \\
\hline
\end{tabular}

\section{Perancangan struktural}

\section{Rangka Alat}

Rangka alat berfungsi untuk menopang semua komponen - komponen yang ada pada alat bahan yang digunakan, besi siku dengan ukuran $2 \mathrm{x}$ $2 \times 1,4 \mathrm{~cm}$, tinggi rangka alat $80 \mathrm{~cm}$, lebar $80 \mathrm{~cm}$.

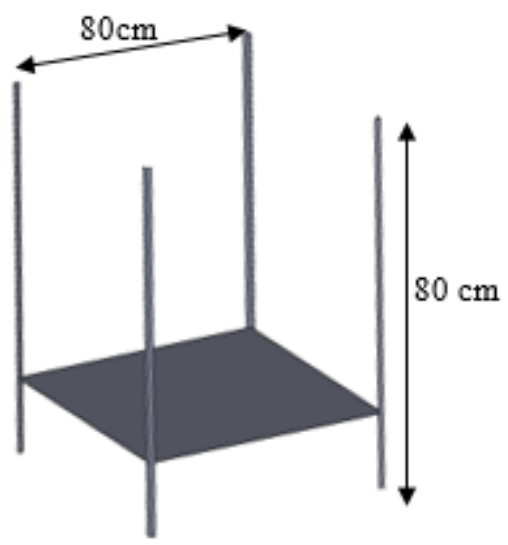

Gambar 3.3. Gambar Rangka 3D

\section{Hoper Bahan Bakar}

Hoper bahan bakar Untuk memasukan bahan bakar yang akan digunakan, bahan yang digunaka plat. Lebar $20 \mathrm{~cm}$ panjang $40 \mathrm{~cm}$.

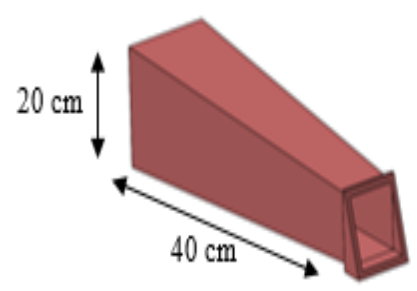

Gambar 3.4 Hoper Bahan Bakar 3D 


\section{Boiler}

Boiler berfungsi untuk proses pembakaran pada alat, bahan yang digunakan pada boiler pipa galfanis $\varnothing 300 \mathrm{~mm}$ tinggi 40 $\mathrm{cm}$.

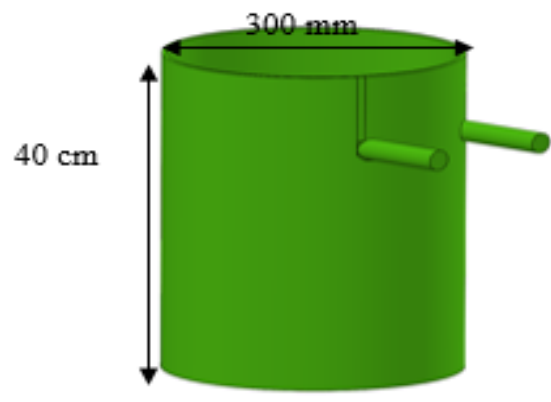

Gambar 3.5. Boiler 3D

\section{Plat Saringan}

Plat saringan berfungsi untuk menyaring bahan bakar dari sisa pembakaran, bahan yang digunakan besi plat panjang $70 \mathrm{~cm}$, lebar $70 \mathrm{~cm}$, tebal $3 \mathrm{~mm} \varnothing$ lubang $3 \mathrm{~mm}$

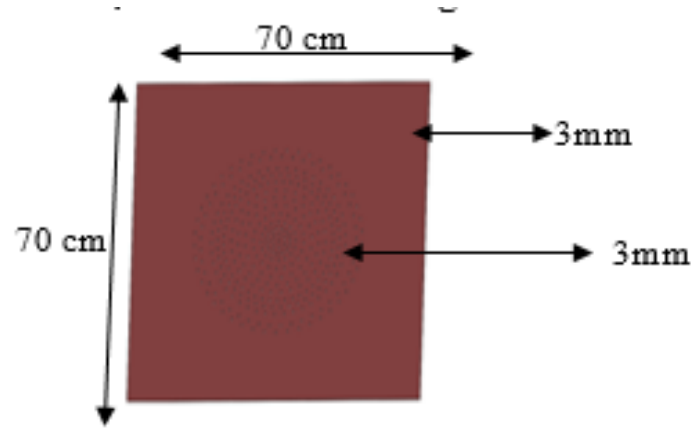

Gambar 3.6. Plat saringan 3D

\section{Laci Penampung}

Laci penampung berfungsi untuk menampung sisah pembakaran yang sudah tersaring. Lebar $75 \mathrm{~cm}$ tinggi $10 \mathrm{~cm}$.

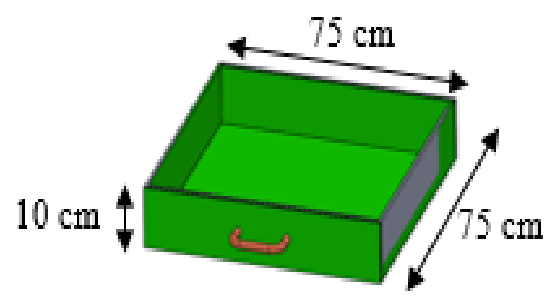

Gambar 3.7.Tempat penampung hasil sisa pembakaran 3D

\section{Kipas Dan Imput Udara Masuk}

Kipas berfugsi untuk mensuplai udara masuk sedangkan Imput udara menerima udara dari kipas dan mengantarnya ke tempat pembakaran agar bersirkulasi dengan baik. Bahan yang digunakan pipa galfanis Panjang 20 $\mathrm{cm}$ tinggi $30 \mathrm{~cm}$.

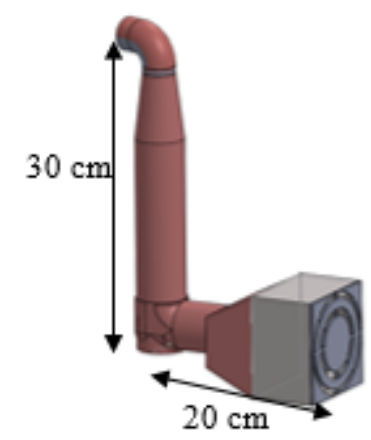

Gambar 3.8. Kipas Dan Input ( Udara masuk) 3D

\section{Output udara keluar}

Output udara keluar berfungsi untuk tempat keluar udara yang akan ke ternak ayam. Bahan yang digunakan besi plat galfanis Panjang $40 \mathrm{~cm}$, lebar $60 \mathrm{~cm}$.

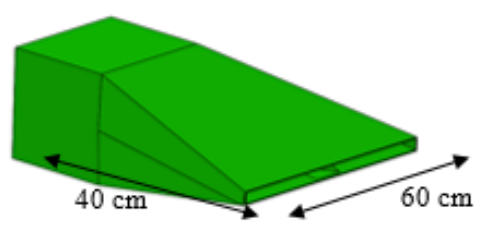

Gambar 3.9. Output (Udara Panas keluar) 3D

\section{Selang penghantar udara}

Tempat untuk sirkulasi udara yang sudah bersirkulasi pada tempat pembakaran bahan yang diguakan slang anti panas. Panjang $200 \mathrm{~cm} \emptyset 20 \mathrm{~mm}$.

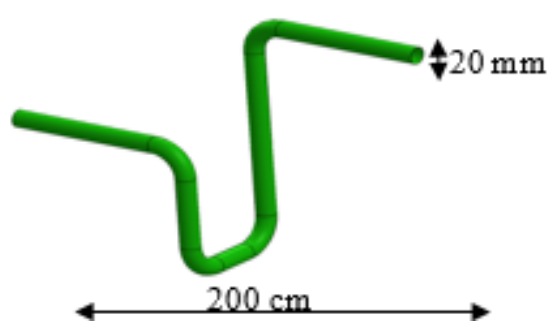

Gambar 3.10. Selang penghantar uap (keluar) $3 \mathrm{D}$ 


\section{Corong Penguapan}

Corong penguapan berfungsi untuk tampat keluar udara/asap dari hasil pembakaran pada boiler, bahan yang digunakan pipa galfanis panjang $100 \mathrm{~cm} \emptyset 50 \mathrm{~mm}$.

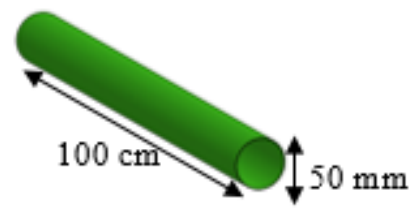

Gambar 3.11. Corong Penguapan 3D

\section{PEMBAHASAN}

\section{Alat Penghangat Ternak Ayam Jenis Pedaging}

Pembuatan alat penghangat ternak ayam pedaging ini, mengunakan sistem simulator boiler dengan memanfaatkan limbah sisa hasil pengolahan pertanian berupa sekam padi. Alat penghangat ternak ayam ini memiliki ranka penopang dari semua komponen dengan tinggi $80 \mathrm{~cm}$ dan lebar $80 \mathrm{~cm}$. Alat penghangat ternak ayam ini dibuat, dilabolaturium peralatan mesin pertanian (MPP) dapat dilihat pada gambar 4.1 sebagai berikut.

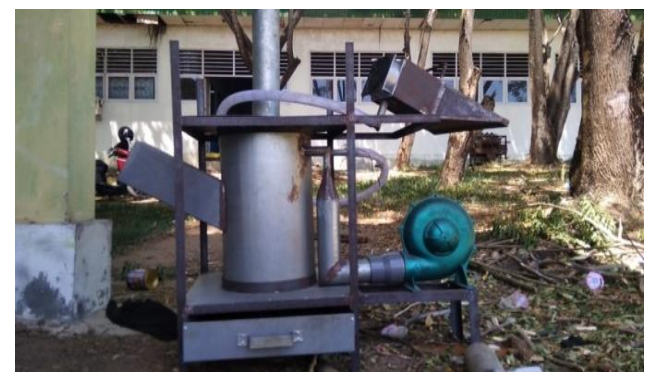

Gambar 4.1 Alat Penghangat Ternak Ayam

Alat penghangat ternak ini memiliki control yang dapat mengontrol suhu yang masuk ke ruang ternak ayam sehinga panas (suhu) yang masuk tidak melebihi suhu yang dibutuhkan ternak ayam.

1. Rangka Alat

2. Hoper Bahan Bakar

3. Boiler

4. Plat Saringan

5. Laci Penampung

6. Kipas

7. Imput uap masuk
8. Output uap keluar
9. Selang penghantar udara
10. Plat Penutup Atas
11. Corong Penguapan
12. Termostat dan Termocoper

\section{Rangka Alat}

Rangka alat berfungsi untuk menopang semua komponen - komponen yang ada pada alat. Sehinga disaat pembuatan rangka harus sangat teliti dan menggunakan bahan yang kuat untuk pembuatan alat, agar rangka tersebut dapat menopang komponen - komponen yang ada pada alat. Bahan yang digunakan, besi siku dengan ukuran 2 × 2 × $1,4 \mathrm{~cm}$, tinggi rangka alat $80 \mathrm{~cm}$, lebar $80 \mathrm{~cm}$.

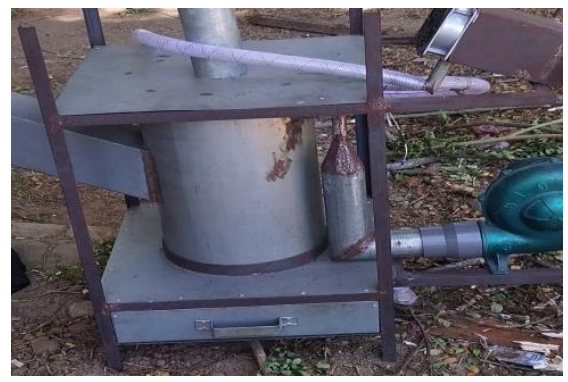

Gambar 4.2 Rangka Alat

\section{Hoper Bahan Bakar}

Hoper bahan bakar merupakan sebuah kompenen yang berfungsi untuk tempat memasukan dan menambahkan bahan bakar, yang akan digunakan pada proses pembakaran dalam boiler. Bahan yang digunaka plat galfanis, Lebar 20 $\mathrm{cm}$ panjang $40 \mathrm{~cm}$

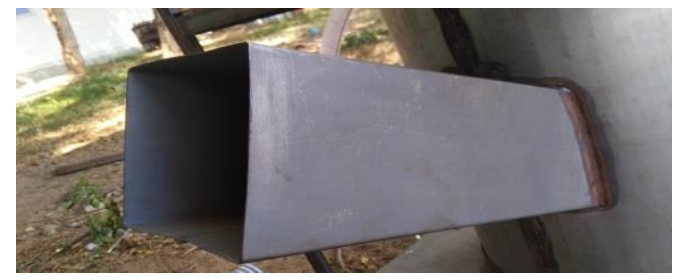

Gambar 4.3 Hoper Bahan Bakar

\section{Boiler}

Boiler merupakan wadah atau tempat untuk proses pembakaran, yang berfungsi untuk memanaskan udara yang dihasilkan dari kipas sebelum disalurkan ke ruang ternak ayam. Bahan 
yang digunakan pada boiler pipa galfanis $\varnothing 300 \mathrm{~mm}$ tinggi $40 \mathrm{~cm}$.

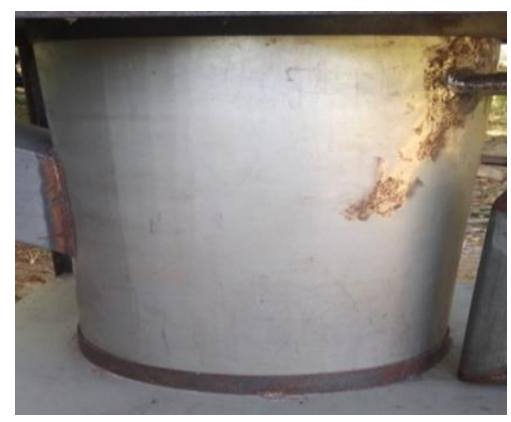

Gambar 4.4 Boiler

\section{Plat Saringan}

Plat saringan berfungsi untuk menyaring bahan bakar dari sisa pembakaran didalam boiler, bahan yang digunakan besi plat panjang $70 \mathrm{~cm}$, lebar $70 \mathrm{~cm}$, tebal $3 \mathrm{~mm} \varnothing$ lubang $3 \mathrm{~mm}$.

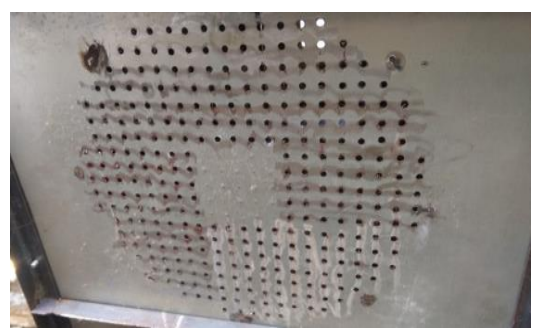

Gambar 4.5 Plat Saringan

\section{Laci Penampung}

Laci penampung berfungsi untuk menampung sisah dari hasil pembakaran didalam boiler yang sudah tersaring. Bahan yang digunakan plat galfanis Lebar $75 \mathrm{~cm}$ tinggi $10 \mathrm{~cm}$.

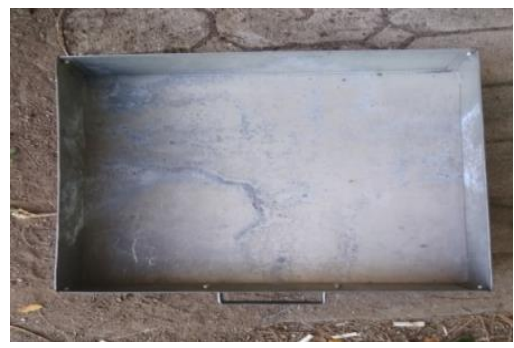

Gambar 4.6 Laci Penampung

\section{Blower Input Udara Masuk}

Blower berfugsi untuk mensuplai udara masuk sedangkan Imput udara menerima udara dari kipas dan mengantarnya ke tempat pembakaran agar bersirkulasi dengan baik. Bahan yang digunakan pipa galfanis Panjang $20 \mathrm{~cm}$ tinggi 30 $\mathrm{cm}$.

\section{Output Udara Keluar}

Output udara keluar berfungsi untuk tempat keluar udara yang akan ke ternak ayam. Bahan yang digunakan besi plat galfanis Panjang $40 \mathrm{~cm}$, lebar $60 \mathrm{~cm}$.

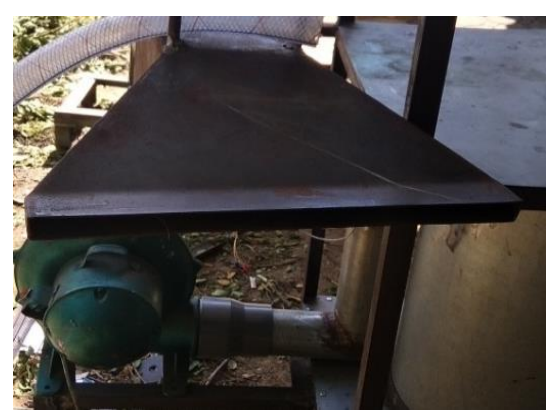

Gambar 4.8 Output Udara Keluar

\section{Selang Pengantar Udara}

Tempat untuk sirkulasi udara yang sudah bersirkulasi pada tempat pembakaran bahan yang diguakan slang anti panas. Panjang $200 \mathrm{~cm} \varnothing 20$ $\mathrm{mm}$.

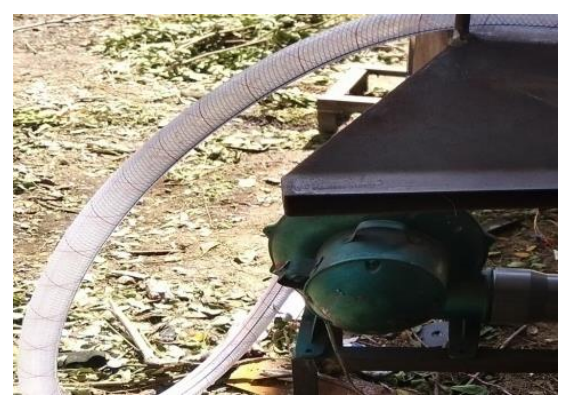

Gambar 4.9 Selang Penghantar udara

\section{Corong Penguapan}

Corong penguapan berfungsi untuk tampat keluar udara/asap dari hasil pembakaran pada boiler, bahan yang digunakan pipa galfanis panjang $100 \mathrm{~cm} \varnothing 50 \mathrm{~mm}$.

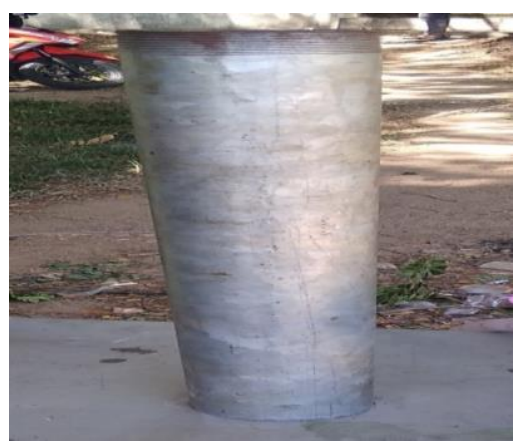

Gambar 4.10 Corong Penguapan 


\section{Termostat dan Thermocouple}

Mengontrol suhu/uap yang dihasilkan dari alat dan mengatur suhu sesuai yang dibutuhkan ternak ayam.

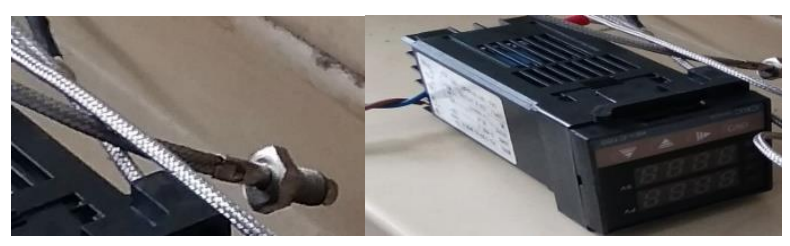

Gambar 4.11 Termostat dan Thermocouple

\section{PENUTUP}

\section{Kesimpulan}

Berdasarkan hasil dari pengujian alat penghangat ternak ayam dengan sistem simulator boiler mengunakan bahan bakar sekam padi maka dapat disimpulkan beberapa hal diantaranya, pada pengujian alat dengan bahan bakar sekam padi $3 \mathrm{~kg} / \mathrm{jam}$ menghasilkan suhu yang lebih baik, dengan rata-rata $44^{\circ} \mathrm{C}$ dibandingkan dengan mengunakan sekam dengan ukuran $1 \mathrm{~kg}$ dan $2 \mathrm{~kg}$. Karena pada saat pembakaran terjadi suhu yang dihasilkan tidak bertahan lama.dan krakteristik yang dihasilkan dalam proses pemberian panas untuk ternak ini berupa udara yang dipanaskan dan disalurkan ke ruang ternak ayam

\section{Saran}

Menggingat skema yang dipakai dalam pembuatan alat ini masi dalam skala simulasi, diharapkan pada saat pembuatan alat dalam skala besar dapat mengunakan bahan yg lebih baik lagi. Misalnya boiler ruang pembakaran dan slang penghantar panas agar dapa menghasilkan, hasil yang lebih baik lagi.

\section{DAFTAR PUSTAKA}

Bps (2018) 'Dengan memperhitungkan potensi dan asumsi luas panen, diperkirakan produksi padi sebesar 241.948 ton GKG'. Available at: https://gorontalo.bps.go.id/pressrelease/20 18/11/01/544/dengan- memperhitungkan potensi-dan-asumsi-luas-panen-diperkirakanproduksi-padi- januari---desember-2018sebesar-241-948-ton-gkg.html.

Houston (1972) 'komposisi sekam padi dan abu sekam padi', pp. 16-29.

Termis (2008) 'Boiler \& pemanas fluida termis 1.', Water, pp. 1-42. Available at: www.energyefficiencyasia.org.

Wibowo, H. and Mesin, J. T. (2008) 'Studi banding konduktifitas panas antara gabus', pp. 112-118. 